\title{
Competition for zinc binding in the host-pathogen interaction
}

\author{
Mauro Cerasi ${ }^{1}$, Serena Ammendola ${ }^{1}$ and Andrea Battistoni ${ }^{1,2 *}$ \\ 1 Dipartimento di Biologia, Università di Roma Tor Vergata, Rome, Italy \\ ${ }^{2}$ Istituto Nazionale Biostrutture e Biosistemi, Consorzio Interuniversitario, Rome, Italy
}

Edited by:

Frédéric J. Veyrier, Institut Pasteur,

France

Reviewed by:

Klaus Hantke, Universität Tübingen, Germany

Robert D. Perry, University of

Kentucky, USA

*Correspondence:

Andrea Battistoni, Via della Ricerca Scientifica, Dipartimento di Biologia, Room 372, Università di Roma Tor Vergata, Rome 00133, Italy

e-mail: andrea.battistoni@

uniroma2.it
Due to its favorable chemical properties, zinc is used as a structural or catalytic cofactor in a very large number of proteins. Despite the apparent abundance of this metal in all cell types, the intracellular pool of loosely bound zinc ions available for biological exchanges is in the picomolar range and nearly all zinc is tightly bound to proteins. In addition, to limit bacterial growth, some zinc-sequestering proteins are produced by eukaryotic hosts in response to infections. Therefore, to grow and multiply in the infected host, bacterial pathogens must produce high affinity zinc importers, such as the ZnuABC transporter which is present in most Gram-negative bacteria. Studies carried in different bacterial species have established that disruption of ZnuABC is usually associated with a remarkable loss of pathogenicity. The critical involvement of zinc in a plethora of metabolic and virulence pathways and the presence of very low number of zinc importers in most bacterial species mark zinc homeostasis as a very promising target for the development of novel antimicrobial strategies.

Keywords: zinc uptake, ZnuABC, antibacterial therapies, metal cofactor, host-pathogen interaction, Salmonella enterica, zinc transporter, nutritional immunity

\section{ZINC: CHEMICAL PROPERTIES AND ROLE IN BACTERIAL PROTEINS}

Among transition metals, zinc is likely the one which is used as a structural or catalytic cofactor in the wider number of proteins. The widespread use of zinc in proteins can be related to its peculiar chemical properties (Andreini et al., 2008). Unlike the other biological relevant transition metals $\left(\mathrm{Fe}^{2+}, \mathrm{Mn}^{2+}, \mathrm{Cu}^{2+}\right.$, $\left.\mathrm{Ni}^{2+}\right)$ the zinc ion $\left(\mathrm{Zn}^{2+}\right)$ has a filled $d$ orbital and, therefore, it is redox stable. Zinc mainly participates to catalytic reactions by acting as a Lewis acid able to accept electron pairs or, as an alternative, by attracting or stabilizing negative charges of the substrates. Moreover, zinc binding to proteins is facilitated by its capability to form stable chemical bonds with nitrogen, oxygen and sulfur atoms and assume different coordination numbers. As a consequence zinc can be found in a large variety of distinct chemical environments, which may significantly modulate its reactivity. However, a potential problem of zinc is that it binds to proteins stronger than the other divalent metals (Irving and Williams, 1948) and, therefore, cells maintain the intracellular pool of "free" metal at very low levels to prevent its unspecific binding to proteins (Colvin et al., 2010).

Different studies have attempted to measure the amount of zinc in bacteria. It has been shown that microorganisms have a remarkable capability to modify their intracellular zinc content in response to variations in the environmental availability of the metal (Outten and O'Halloran, 2001; Garmory and Titball, 2004) and that the total cellular zinc in bacteria growing in rich media is in the submillimolar range $\left(10^{-4} \mathrm{M}\right)$, i.e., a concentration comparable to that usually observed in most eukaryotic cells (Eide, 2006). More complex is to obtain a careful evaluation of the intracellular pool of metal ions not tightly bound to proteins. In vitro studies carried out with purified zinc-responding transcriptional regulators have initially suggested that cellular "free" zinc levels are in the femtomolar range, i.e., around $10^{-15} \mathrm{M}$ (Outten and O'Halloran, 2001). However, recent studies involving proteinbased ratiometric biosensors have established that in vivo the concentration of intracellular exchangeable zinc is around $20 \mathrm{pM}$, i.e., $2 \times 10^{-11} \mathrm{M}$ (Wang et al., 2011). Picomolar values of "free" zinc have been reported also in several eukaryotic systems (Colvin et al., 2010).

Interestingly, although the zinc concentration in bacterial cells is close to that of iron, a significant fraction of iron may be found in association to proteins such as ferritins, bacterioferritins or DPS (Andrews et al., 2003), whereas bona fide zinc-storage proteins are present only in a few bacteria (Blindauer et al., 2002). An experimental attempt to explore the complexity of the bacterial zinc proteome has shown that more than $3 \%$ of the proteins expressed in Escherichia coli contain zinc (Katayama et al., 2002), whereas bioinformatics investigations have revealed that about $5 \%$ of all bacterial proteins contain recognizable zinc-binding sites (Andreini et al., 2006). This means that an E. coli cell with about 4300 protein-encoding genes contains more than 200 zincbinding proteins. These figures, however, are not sufficient to have an accurate idea of the actual importance of this metal in the physiology of a bacterial cell. In fact, in addition to being an essential cofactor in a large number of enzymes involved in central metabolic pathways, zinc is bound to several proteins involved in the management of gene expression, including some ribosomal proteins (Hensley et al., 2011), RNA polymerases (Scrutton et al., 1971), tRNA synthetases (Miller et al., 1991), sigma factor interacting proteins (Campbell et al., 2007) and zinc responding transcriptional factors (Chivers, 2007). Moreover, zinc is involved 
in other crucial processes, including DNA repair (Kropachev et al., 2006), response to oxidative stress (Ortiz De Orue Lucana et al., 2012), antibiotic resistance (Meini et al., 2013) and production of virulence-related proteins (Ammendola et al., 2008). It follows that changes in the intracellular concentrations of zinc can have pleiotropic effects on the composition of the bacterial proteome, involving changes in the expression and activity of zinc-containing proteins as well as of proteins which do not employ this cofactor.

\section{BACTERIAL ZINC UPTAKE SYSTEMS AND RESPONSE TO ZINC SHORTAGE}

Although in bacteria exposed to high levels of zinc the metal may enter through a large number of unspecific channels, only a few metal transporters are known to mediate the specific uptake of zinc (Hantke, 2005) (Figure 1). Some recent studies on the pneumococcal PsaA protein involved in manganese uptake have provided interesting hints to understand the mechanisms ensuring specificity in transition metal import (McDevitt et al., 2011; Counago et al., 2013). PsaA may bind either manganese or other first-row transition metals, but, due to the propensity of zinc to form stable complexes with proteins (Irving and Williams, 1948) it competitively affects $\mathrm{Mn}^{2+}$ binding and locks the protein in a conformation which prevents the entry either of zinc or of manganese. This observation provides an explanation for the ability of zinc to inhibit pneumococcal growth (McDevitt et al., 2011) and an elegant example of the strategies used by living cells to guarantee the correct uptake of specific metal ions (Waldron and Robinson, 2009).

In several Gram-negative bacteria growing in metal replete conditions, zinc uptake is thought to be primarily mediated by ZupT, a constitutively expressed low affinity transporter belonging to the ZIP (ZRT-, IRT-like Protein) protein family (Grass et al., 2002). This metal permease has a broad metal specificity, but it displays a clear preference for zinc over other divalent metals (Grass et al., 2005). ZupT depends on the proton motive force to energize zinc import (Karlinsey et al., 2010; Taudte and Grass, 2010).

The response to zinc paucity is controlled through the coordinated expression of a set of genes regulated by the transcriptional factor Zur, which may bind two or more zinc ions, depending on the species (Outten et al., 2001; Lucarelli et al., 2007; Shin et al., 2011). One atom of zinc serves a structural role, whereas the other atom(s) favors the folding of a DNA-binding domain enabling the protein to tightly bind to a consensus sequence located in the promoter of said genes. In contrast, when the intracellular zinc content decreases, zinc-devoid Zur is no longer able to stably interact with DNA and to repress transcription. The number of known Zur-regulated genes changes in different bacteria, but in all species they include a small operon encoding for the components of ZnuABC, a high affinity zinc importer of the ABC family, and one or more genes encoding for paralogs of zinccontaining ribosomal proteins (Panina, 2003; Graham et al., 2009; Li et al., 2009; Lim et al., 2013). The ZnuABC uptake system is composed of three proteins: the ZnuB channel, the ZnuC ATPase component which provides the energy necessary for ion transport through the inner membrane, and $\mathrm{ZnuA}$, a soluble protein which captures $\mathrm{Zn}$ (II) in the periplasm with high efficiency and delivers it to ZnuB (Patzer and Hantke, 1998). In some bacteria there is also an accessory component of the ZnuABC transporter, ZinT, which is known to form a complex with ZnuA in presence of zinc and is thought to enhance ZnuA ability to recruit zinc (Petrarca et al., 2010; Ilari et al., 2013). A similar zinc uptake system (AdcABC) can be found in pneumococci and some other Gram-positive bacteria, where the lipoprotein AdcA is characterized by two structural domains that show clear sequence and structural homology with ZnuA and ZinT, respectively (Dintilhac et al., 1997; Panina et al., 2003).

An interesting facet of the Zur-mediated response to zinc shortage is the substitution of ribosomal proteins containing zinc with homologous proteins lacking the zinc-binding motif. This change in ribosomal structure reduces the metal requirements of bacterial cells, as the majority of intracellular zinc is thought to be associated to ribosomes (Hensley et al., 2011). Moreover, the production of zinc-independent ribosomal proteins may be useful to mobilize a relevant amount of metal from pre-existing ribosomes and facilitates the adaptation to zinc-limiting conditions (Gabriel and Helmann, 2009). From this point of view, the ribosome may be described as a zinc storage protein complex. Additional paralogs of zinc-containing proteins have been identified in several bacteria (Haas et al., 2009) and include a homolog of the transcriptional factor DksA which is involved in the control of the bacterial response to stress and starvation (Blaby-Haas et al., 2011).

The outer membrane of Gram-negative bacteria allows the passive diffusion of low molecular weight molecules. However, a mechanism of nutrient uptake solely based on diffusion may be hardly able to ensure the adequate absorption of elements which are poorly available in the environment. In recent years, an outer membrane TonB-dependent receptor involved in zinc uptake has been identified in Neisseria meningitidis and some other Gramnegative bacteria (Stork et al., 2010). This protein, denominated ZnuD, mediates either zinc or heme uptake and is regulated either by Zur or by Fur (Kumar et al., 2012; Pawlik et al., 2012). The pneumococcal surface protein $\mathrm{PhtD}$ has been proposed to play a functionally similar role in favoring zinc uptake through AdcAII (Loisel et al., 2011). No outer membrane zinc receptors have been so far identified in Enterobacteria or in other Gram-negative bacteria. However, it has been observed that apo-ZinT can be extruded outside the cell, suggesting that it could have some role in the acquisition of zinc from the environment (Ho et al., 2008; Gabbianelli et al., 2011).

It should also be noted that a few bacterial species have been shown to express more than one high affinity zinc uptake systems. This is the case of Listeria monocytogenes which expresses two ABC-type zinc importers (ZnuABC and ZurAM), both contributing to full virulence (Corbett et al., 2012) and of nontypeable Haemophilus influenzae, where the zinc binding system ZevAB facilitates growth in zinc-limiting conditions and lung colonization in infected mice (Rosadini et al., 2011). Similarly, disruption of znuA in Pseudomonas aeruginosa results in a very limited growth defect under zinc-limiting conditions (Ellison et al., 2013), possibly due to the expression of a zinc-importing P-type ATPase (Lewinson et al., 2009). 


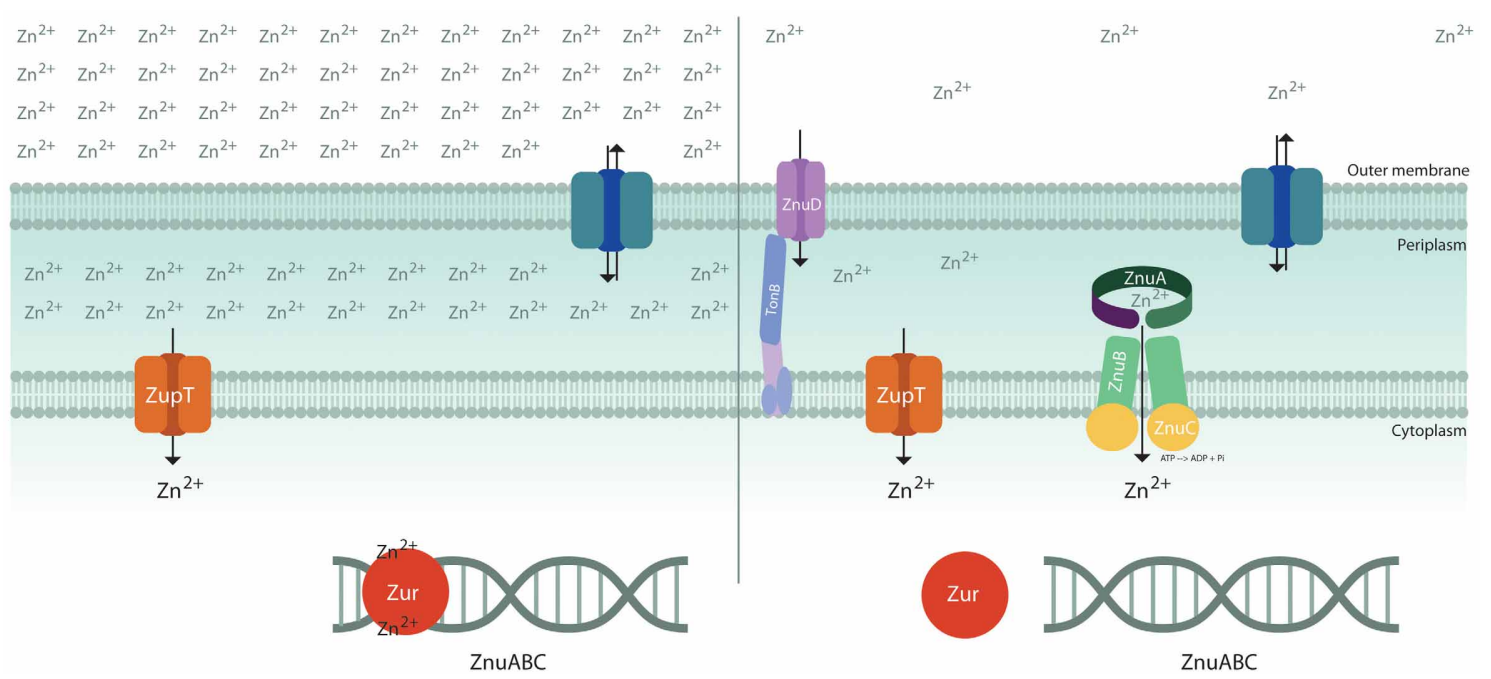

FIGURE 1 | Schematic diagram of transporters involved in zinc uptake. The bacterial outer membrane is thought to be permeable to hydrophilic solutes of $<600$ dalton (Nikaido and Vaara, 1985) and, therefore, zinc concentration in the periplasmic space is largely dependent on zinc availability in the environment. Under zinc replete conditions (left), the metal is imported through low affinity import systems, such as ZupT, and Zur inhibits the expression of the importer ZnuABC. Under conditions of zinc shortage (right), apoZur is unable to bind DNA and the high affinity zinc importer ZnuABC is expressed. Neisseria meningitidis expresses a Zur-regulated TonB-dependent outer membrane protein, ZnuD, involved in zinc uptake.

\section{ZINC IN THE HOST-PATHOGEN INTERACTION}

Whereas the competition for iron acquisition has been recognized as a key element of the host pathogen interaction for a long time, only in recent years the efficient uptake of other divalent metals has emerged to play a comparable role (Kehl-Fie and Skaar, 2010). In particular the importance of zinc has become clear through a series of investigations which have established that deletion of the $z n u A B C$ genes not only decrease bacterial ability to growth in in vitro environments poor of this metal, but also dramatically affects their pathogenicity. Bacterial pathogens which have been shown to critically depend on ZnuABC to infect their hosts include Acinetobacter baumannii (Hood et al., 2012), Brucella abortus (Kim et al., 2004; Yang et al., 2006), Campylobacter jejuni (Davis et al., 2009), pathogenic E. coli strains (Sabri et al., 2009; Gabbianelli et al., 2011), H. ducreyi (Lewis et al., 1999), Moraxella catarrhalis (Murphy et al., 2013), Pasteurella multocida (Garrido et al., 2003), Salmonella enterica (Campoy et al., 2002; Ammendola et al., 2007) and Yersinia ruckeri (Dahiya and Stevenson, 2010). In contrast, while being required for zinc uptake in vitro, ZnuABC does not contribute to $Y$. pestis virulence (Desrosiers et al., 2010) and provides only a limited advantage to Proteus mirabilis during urinary tract infections (Nielubowicz et al., 2010). It is not yet clear whether these bacteria possess additional zinc importers or if they show limited zinc requirements during infections.

Probably, the previous underestimation of the importance of zinc in the interaction between bacteria and their hosts can be largely attributed to the apparent abundance of this element in all tissues. In fact, high levels of zinc are present either within cells or in the plasma, where most of the metal is loosely associated to proteins (Zalewski et al., 2006) and, therefore, potentially available for invading microorganisms. However, it should be noted that a typical feature of the early response to the infection is the rapid fall of plasma zinc concentration, accompanied by zinc accumulation in the liver. Redistribution of zinc among the various tissues is regulated by a lipopolysaccharide-induced cytokines cascade (with IL-6 playing a central role) which stimulates increased synthesis of acute phase proteins, such as metallothionein, and the hepatic uptake of the metal through the induction of the solute carrier 39 (SLC39) protein ZIP14 (Liuzzi, 2005). In view of the importance of the ZnuABC transporter in bacterial zinc uptake during infections, this feature of the acute phase response appears as an adaptive mechanism intended to deprive pathogens of zinc.

The role of the ZnuABC transporter has been investigated in details in $S$. enterica serovar Typhimurium (S. Typhimurium). Expression of $z n u A B C$ is repressed in $S$. Typhimurium cultivated in synthetic media containing zinc concentrations as low as $1 \mu \mathrm{M}$. In contrast, the $z n u A B C$ operon is strongly induced in bacteria recovered from the spleens of infected mice or from cultured epithelial or macrophagic cells (Ammendola et al., 2007). These observations suggest that zinc bound to proteins is not easily available for invading bacteria and that $\mathrm{ZnuABC}$ is required to have rapid access to the pool of "free" zinc. More recently, it has been shown that during gut infections ZnuABC confers resistance to the antimicrobial protein calprotectin (Liu et al., 2012). Calprotectin is a neutrophilic protein of the S100 family of calcium binding proteins, that is abundantly released at sites of infection to control the multiplication of pathogens by the sequestration of zinc and manganese (Kehl-Fie and Skaar, 2010). In support to the experimental evidence that calprotectin starves bacteria for metal ions, structural studies have confirmed that calprotectin possesses two distinct binding sites for transition metals, one of which is specific for zinc and the other one may 
accommodate either zinc or manganese (Brunjes Brophy et al., 2013; Damo et al., 2013). Bacteria expressing ZnuABC are able to resist to such antimicrobial strategy and this favor their growth over competing microbes in the inflamed gut (Gielda and Dirita, 2012; Liu et al., 2012). Taken together, these studies suggest that zinc acquisition through the ZnuABC transporter is essential for the colonization of Salmonella in mice, and provide a parallelism between the mechanisms of iron and zinc sequestration in the host-pathogen relationships. It is worth noting that calprotectin is not the unique S100 protein involved in zinc sequestration. In fact, a comparable function has been proposed for the antibacterial protein psoriasin (S100A7), which protects human skin from E. coli infections (Glaser et al., 2005).

Although, the above mentioned studies have suggested that zinc sequestration is a strategy widely used by vertebrates to control microbial infections, a few recent observations have revealed an alternative way to use zinc in host defense. In fact, it has been shown that human macrophages control mycobacteria by elevating zinc levels in the bacteria-containing phagosomes (Botella et al., 2011). This process is dependent on reactive oxygen species generated by the phagocytic NADPH oxidase and involves the mobilization of zinc from intracellular stores. Mycobacterial resistance to zinc intoxication in macrophages relies on their ability to induce the expression of heavy metal efflux P-type ATPases, which prevent the intracellular accumulation of zinc at toxic levels. Structurally homologous zinc efflux pumps have been identified in a large number of bacteria, including E. coli, where the P-type zinc exporter ZntA has been proved to be critical for zinc tolerance (Beard et al., 1997; Rensing et al., 1997) and for the maintaining of appropriate levels of intracellular zinc (Wang et al., 2012). Whereas mycobacteria lacking the efflux pump CtpC or $E$. coli cells devoid of ZntA display a reduced ability to survive in human macrophages, disruption of CtpC does not affect the ability of M. tuberculosis to infect mice (Botella et al., 2011).

To add to the complexity, a mobilization of zinc in the opposite direction to that found in response to mycobacteria has been observed in murine macrophages infected with the fungus Histoplasma capsulatum (Subramanian Vignesh et al., 2013). In this case, phagosomes are deprived of zinc and the metal accumulates in the Golgi or in the cytoplasm, in association to metallothioneins. Further studies are needed to understand whether these different responses depend on the cross-talk between each specific microorganism and phagocytic cells, or whether the ability to poison bacteria through an excess of zinc is a prerogative of human macrophages.

\section{ZINC HOMEOSTASIS AS A TARGET FOR ANTIBACTERIAL THERAPIES}

Different studies have proposed that ABC transporters could be effective targets for the development of novel antibacterial drugs or vaccines (Garmory and Titball, 2004; Counago et al., 2012). In this view, ZnuABC appears as a particularly promising candidate.

Whereas a large number of pathogens produce multiple metal import systems that enable the uptake of different iron forms (reduced or oxidized, "free" or bound to proteins or to heme), in most bacteria there is only one high affinity zinc importer. Moreover, it has been shown that Salmonella strains lacking the whole $z n u A B C$ operon display the same dramatic loss of virulence of strains producing ZnuB and ZnuC, but lacking ZnuA (Petrarca et al., 2010). This finding indicates that the ability of ZnuA to effectively compete for zinc binding with other periplasmic proteins is critical to ensure zinc import in the cytoplasm (Berducci et al., 2004) and suggests that drugs targeting the soluble component of the transporter could block zinc import. This is a very interesting possibility because ZnuA is a suitable substrate for biochemical and structural studies (Banerjee et al., 2003; Chandra et al., 2007; Wei et al., 2007; Yatsunyk et al., 2008; Ilari et al., 2011; Castelli et al., 2013). It is worth noting that several molecules able to interfere with zinc uptake in Candida albicans have been recently identified through the screening of a small-molecule library of 2000 compounds (Simm et al., 2011), thus providing a proof of concept that it is possible to pharmacologically target zinc homeostasis in pathogenic microorganisms.

Bacterial mutant strains unable to produce the ZnuABC transporter are also putative candidate for the development of liveattenuated vaccines. It has been shown that a $S$. Typhimurium $z n u A B C$ strain is able to induce short lasting infections in mice which induce a solid and durable immune-based protection against virulent strains of $S$. Typhimurium (Pasquali et al., 2008; Pesciaroli et al., 2011). The same strain proved to be attenuated, immunogenic and protective also in pigs (Gradassi et al., 2013; Pesciaroli et al., 2013). Similarly, it has been shown that vaccination with Brucella znuA mutants protects mice from Brucella infections (Yang et al., 2006; Clapp et al., 2011). In addition, it has been shown that $\mathrm{ZnuD}$ is able to elicit the production of antibodies triggering complement-mediated killing of several Neisseria meningitidis serogroup B strains, suggesting that it is a promising candidate for the generation of an effective vaccine (Hubert et al., 2013). Taken together, these studies suggest that zinc homeostasis offers interesting options to generate vaccines against different pathogenic bacteria.

\section{REFERENCES}

Ammendola, S., Pasquali, P., Pacello, F., Rotilio, G., Castor, M., Libby, S. J., et al. (2008). Regulatory and structural differences in the $\mathrm{Cu}, \mathrm{Zn}$-superoxide dismutases of Salmonella enterica and their significance for virulence. J. Biol. Chem. 283, 13688-13699. doi: 10.1074/jbc.M710499200

Ammendola, S., Pasquali, P., Pistoia, C., Petrucci, P., Petrarca, P., Rotilio, G., et al. (2007). High-affinity $\mathrm{Zn} 2+$ uptake system $\mathrm{ZnuABC}$ is required for bacterial zinc homeostasis in intracellular environments and contributes to the virulence of Salmonella enterica. Infect. Immun. 75, 5867-5876. doi: 10.1128/ IAI.00559-07

Andreini, C., Banci, L., Bertini, I., and Rosato, A. (2006). Zinc through the three domains of life. J. Proteome Res. 5, 3173-3178. doi: 10.1021/pr0603699

Andreini, C., Bertini, I., Cavallaro, G., Holliday, G. L., and Thornton, J. M. (2008). Metal ions in biological catalysis: from enzyme databases to general principles. J. Biol. Inorg. Chem. 13, 1205-1218. doi: 10.1007/s00775-008-0404-5

Andrews, S. C., Robinson, A. K., and Rodríguez-Quiñones, F. (2003). Bacterial iron homeostasis. FEMS Microbiol. Rev. 27, 215-237. doi: 10.1016/S01686445(03)00055-X

Banerjee, S., Wei, B., Bhattacharyya-Pakrasi, M., Pakrasi, H. B., and Smith, T. J. (2003). Structural determinants of metal specificity in the zinc transport protein ZnuA from synechocystis 6803. J. Mol. Biol. 333, 1061-1069. doi: 10.1016/j.jmb.2003.09.008

Beard, S. J., Hashim, R., Membrillo-Hernandez, J., Hughes, M. N., and Poole, R. K. (1997). Zinc(II) tolerance in Escherichia coli K-12: evidence that the zntA gene (o732) encodes a cation transport ATPase. Mol. Microbiol. 25, 883-891. doi: 10.1111/j.1365-2958.1997.mmi518.x 
Berducci, G., Mazzetti, A. P., Rotilio, G., and Battistoni, A. (2004). Periplasmic competition for zinc uptake between the metallochaperone $\mathrm{ZnuA}$ and $\mathrm{Cu}, \mathrm{Zn}$ superoxide dismutase. FEBS Lett. 569, 289-292. doi: 10.1016/j.febslet.2004.06.008

Blaby-Haas, C. E., Furman, R., Rodionov, D. A., Artsimovitch, I., and De Crécy-Lagard, V. (2011). Role of a Zn-independent DksA in Zn homeostasis and stringent response. Mol. Microbiol. 79, 700-715. doi: 10.1111/j.13652958.2010.07475.x

Blindauer, C. A., Harrison, M. D., Robinson, A. K., Parkinson, J. A., Bowness, P. W., Sadler, P. J., et al. (2002). Multiple bacteria encode metallothioneins and SmtA-like zinc fingers. Mol. Microbiol. 45, 1421-1432. doi: 10.1046/j.13652958.2002.03109.x

Botella, H., Peyron, P., Levillain, F., Poincloux, R., Poquet, Y., Brandli, I., et al. (2011). Mycobacterial $\mathrm{p}(1)$-type ATPases mediate resistance to zinc poisoning in human macrophages. Cell Host Microbe 10, 248-259. doi: 10.1016/j.chom.2011.08.006

Brunjes Brophy, M., Nakashige, T. G., Gaillard, A., and Nolan, E. M. (2013). Contributions of the S100A9 C-terminal tail to high-affinity Mn(II) chelation by the host-defense protein human calprotectin. J. Am. Chem. Soc. 135 17804-17817. doi: 10.1021/ja407147d

Campbell, E. A., Greenwell, R., Anthony, J. R., Wang, S., Lim, L., Das, K., et al. (2007). A conserved structural module regulates transcriptional responses to diverse stress signals in bacteria. Mol. Cell 27, 793-805. doi: 10.1016/j.molcel.2007.07.009

Campoy, S., Jara, M., Busquets, N., Perez De Rozas, A. M., Badiola, I., and Barbe, J. (2002). Role of the high-affinity zinc uptake znuABC system in Salmonella enterica serovar typhimurium virulence. Infect. Immun. 70, 4721-4725. doi: 10.1128/IAI.70.8.4721-4725.2002

Castelli, S., Stella, L., Petrarca, P., Battistoni, A., Desideri, A., and Falconi, M. (2013). Zinc ion coordination as a modulating factor of the ZnuA histidinerich loop flexibility: a molecular modeling and fluorescence spectroscopy study. Biochem. Biophys. Res. Commun. 430, 769-773. doi: 10.1016/j.bbrc.2012.11.073

Chandra, B. R., Yogavel, M., and Sharma, A. (2007). Structural analysis of ABC-family periplasmic zinc binding protein provides new insights into mechanism of ligand uptake and release. J. Mol. Biol. 367, 970-982. doi: 10.1016/j.jmb.2007.01.041

Chivers, P. T. (2007). A galvanizing story-protein stability and zinc homeostasis. J. Bacteriol. 189, 2953-2954. doi: 10.1128/JB.00173-07

Clapp, B., Skyberg, J. A., Yang, X., Thornburg, T., Walters, N., and Pascual, D. W. (2011). Protective live oral brucellosis vaccines stimulate Th1 and th17 cell responses. Infect. Immun. 79, 4165-4174. doi: 10.1128/IAI.05080-11

Colvin, R. A., Holmes, W. R., Fontaine, C. P., and Maret, W. (2010). Cytosolic zinc buffering and muffling: their role in intracellular zinc homeostasis. Metallomics 2, 306-317. doi: 10.1039/b926662c

Corbett, D., Wang, J., Schuler, S., Lopez-Castejon, G., Glenn, S., Brough, D., et al. (2012). Two zinc uptake systems contribute to the full virulence of Listeria monocytogenes during growth in vitro and in vivo. Infect. Immun. 80, 14-21. doi: 10.1128/IAI.05904-11

Counago, R. M., McDevitt, C. A., Ween, M. P., and Kobe, B. (2012). Prokaryotic substrate-binding proteins as targets for antimicrobial therapies. Curr. Drug Targets 13, 1400-1410. doi: 10.2174/138945012803530170

Counago, R. M., Ween, M. P., Begg, S. L., Bajaj, M., Zuegg, J., O’Mara, M. L., et al. (2013). Imperfect coordination chemistry facilitates metal ion release in the Psa permease. Nat. Chem. Biol.

Dahiya, I., and Stevenson, R. M. (2010). The ZnuABC operon is important for Yersinia ruckeri infections of rainbow trout, Oncorhynchus mykiss (Walbaum). J. Fish Dis. 33, 331-340. doi: 10.1111/j.1365-2761.2009.01125.x

Damo, S. M., Kehl-Fie, T. E., Sugitani, N., Holt, M. E., Rathi, S., Murphy, W. J., et al. (2013). Molecular basis for manganese sequestration by calprotectin and roles in the innate immune response to invading bacterial pathogens. Proc. Natl. Acad. Sci. U.S.A. 110, 3841-3846. doi: 10.1073/pnas.1220341110

Davis, L. M., Kakuda, T., and Dirita, V. J. (2009). A Campylobacter jejuni znuA orthologue is essential for growth in low-zinc environments and chick colonization. J. Bacteriol. 191, 1631-1640. doi: 10.1128/JB.01394-08

Desrosiers, D. C., Bearden, S. W., Mier, I. Jr., Abney, J., Paulley, J. T., Fetherston, J. D., et al. (2010). Znu is the predominant zinc importer in Yersinia pestis during in vitro growth but is not essential for virulence. Infect. Immun. 78, 5163-5177. doi: 10.1128/IAI.00732-10

Dintilhac, A., Alloing, G., Granadel, C., and Claverys, J. P. (1997). Competence and virulence of Streptococcus pneumoniae: Adc and PsaA mutants exhibit a requirement for $\mathrm{Zn}$ and $\mathrm{Mn}$ resulting from inactivation of putative ABC metal permeases. Mol. Microbiol. 25, 727-739. doi: 10.1046/j.13652958.1997.5111879.x

Eide, D. J. (2006). Zinc transporters and the cellular trafficking of zinc. Biochim Biophys. Acta 1763, 711-722. doi: 10.1016/j.bbamcr.2006.03.005

Ellison, M. L., Farrow, J. M., Parrish, W., Danell, A. S., and Pesci, E. C. (2013). The Transcriptional regulator Np20 Is the Zinc uptake regulator in Pseudomonas aeruginosa. PLoS ONE 8:e75389. doi: 10.1371/journal.pone.0075389

Gabbianelli, R., Scotti, R., Ammendola, S., Petrarca, P., Nicolini, L., and Battistoni, A. (2011). Role of ZnuABC and ZinT in Escherichia coli O157:H7 zinc acquisition and interaction with epithelial cells. BMC Microbiol. 11:36. doi: 10.1186/1471-2180-11-36

Gabriel, S. E., and Helmann, J. D. (2009). Contributions of Zur-controlled ribosomal proteins to growth under zinc starvation conditions. J. Bacteriol. 191, 6116-6122. doi: 10.1128/JB.00802-09

Garmory, H. S., and Titball, R. W. (2004). ATP-binding cassette transporters are targets for the development of antibacterial vaccines and therapies. Infect. Immun. 72, 6757-6763. doi: 10.1128/IAI.72.12.6757-6763.2004

Garrido, M. E., Bosch, M., Medina, R., Llagostera, M., Perez De Rozas, A. M., Badiola, I., et al. (2003). The high-affinity zinc-uptake system znu$\mathrm{ACB}$ is under control of the iron-uptake regulator (fur) gene in the animal pathogenPasteurella multocida. FEMS Microbiol. Lett. 221, 31-37. doi: 10.1016/S0378-1097(03)00131-9

Gielda, L. M., and Dirita, V. J. (2012). Zinc competition among the intestinal microbiota. MBio 3, e00171-00112. doi: 10.1128/mBio.00171-12

Glaser, R., Harder, J., Lange, H., Bartels, J., Christophers, E., and Schroder, J. M. (2005). Antimicrobial psoriasin (S100A7) protects human skin from Escherichia coli infection. Nat. Immunol. 6, 57-64. doi: 10.1038/ni1142

Gradassi, M., Pesciaroli, M., Martinelli, N., Ruggeri, J., Petrucci, P., Hassan, W. H., et al. (2013). Attenuated Salmonella enterica serovar Typhimurium lacking the ZnuABC transporter: an efficacious orally-administered mucosal vaccine against salmonellosis in pigs. Vaccine 31, 3695-3701 doi: 10.1016/j.vaccine.2013.05.105

Graham, A. I., Hunt, S., Stokes, S. L., Bramall, N., Bunch, J., Cox, A. G., et al. (2009). Severe zinc depletion of Escherichia coli: roles for high affinity zinc binding by ZinT, zinc transport and zinc-independent proteins. J. Biol. Chem. 284, 18377-18389. doi: 10.1074/jbc.M109.001503

Grass, G., Franke, S., Taudte, N., Nies, D. H., Kucharski, L. M., Maguire, M. E., et al. (2005). The metal permease ZupT from Escherichia coli is a transporter with a broad substrate spectrum. J. Bacteriol. 187, 1604-1611. doi: 10.1128/JB.187.5.1604-1611.2005

Grass, G., Wong, M. D., Rosen, B. P., Smith, R. L., and Rensing, C. (2002). ZupT is a $\mathrm{Zn}(\mathrm{II})$ uptake system in Escherichia coli. J. Bacteriol. 184, 864-866. doi 10.1128/JB.184.3.864-866.2002

Haas, C. E., Rodionov, D. A., Kropat, J., Malasarn, D., Merchant, S. S., and De Crecy-Lagard, V. (2009). A subset of the diverse COG0523 family of putative metal chaperones is linked to zinc homeostasis in all kingdoms of life. BMC Genomics 10:470. doi: 10.1186/1471-2164-10-470

Hantke, K. (2005). Bacterial zinc uptake and regulators. Curr. Opin. Microbiol. 8, 196-202. doi: 10.1016/j.mib.2005.02.001

Hensley, M. P., Tierney, D. L., and Crowder, M. W. (2011). Zn(II) binding to Escherichia coli 70 S ribosomes. Biochemistry 50, 9937-9939. doi: 10.1021/bi200619w

Ho, T. D., Davis, B. M., Ritchie, J. M., and Waldor, M. K. (2008). Type 2 secretion promotes enterohemorrhagic Escherichia coli adherence and intestinal colonization. Infect. Immun. 76, 1858-1865. doi: 10.1128/IAI. 01688-07

Hood, M. I., Mortensen, B. L., Moore, J. L., Zhang, Y., Kehl-Fie, T. E., Sugitani, N., et al. (2012). Identification of an Acinetobacter baumannii zinc acquisition system that facilitates resistance to calprotectin-mediated zinc sequestration. PLoS Pathog. 8:e1003068. doi: 10.1371/journal.ppat.1003068

Hubert, K., Devos, N., Mordhorst, I., Tans, C., Baudoux, G., Feron, C., et al. (2013). ZnuD, a potential candidate for a simple and universal Neisseria meningitidis vaccine. Infect. Immun. 81, 1915-1927. doi: 10.1128/IAI. 01312-12

Ilari, A., Alaleona, F., Petrarca, P., Battistoni, A., and Chiancone, E. (2011). The Xray structure of the zinc transporter ZnuA from Salmonella enterica discloses a unique triad of zinc-coordinating histidines. J. Mol. Biol. 409, 630-641. doi: 10.1016/j.jmb.2011.04.036 
Ilari, A., Alaleona, F., Tria, G., Petrarca, P., Battistoni, A., Zamparelli, C., et al. (2013). The Salmonella enterica ZinT structure, zinc affinity and interaction with the high-affinity uptake protein ZnuA provide insight into the management of periplasmic zinc. Biochim. Biophys. Acta 1840, 535-544. doi: 10.1016/j.bbagen.2013.10.010

Irving, H., and Williams, R. J. P. (1948). Order of stability of metal complexes. Nature 162, 746-747. doi: 10.1038/162746a0

Karlinsey, J. E., Maguire, M. E., Becker, L. A., Crouch, M. L., and Fang, F. C. (2010). The phage shock protein PspA facilitates divalent metal transport and is required for virulence of Salmonella enterica sv. Typhimurium. Mol. Microbiol. 78, 669-685. doi: 10.1111/j.1365-2958.2010.07357.x

Katayama, A., Tsujii, A., Wada, A., Nishino, T., and Ishihama, A. (2002). Systematic search for zinc-binding proteins in Escherichia coli. Eur. J. Biochem. 269, 2403-2413. doi: 10.1046/j.1432-1033.2002.02900.x

Kehl-Fie, T. E., and Skaar, E. P. (2010). Nutritional immunity beyond iron: a role for manganese and zinc. Curr. Opin. Chem. Biol. 14, 218-224. doi: 10.1016/j.cbpa.2009.11.008

Kim, S., Watanabe, K., Shirahata, T., and Watarai, M. (2004). Zinc uptake system (znuA locus) of Brucella abortus is essential for intracellular survival and virulence in mice. J. Vet. Med. Sci. 66, 1059-1063. doi: 10.1292/jvms.66.1059

Kropachev, K. Y., Zharkov, D. O., and Grollman, A. P. (2006). Catalytic mechanism of Escherichia coli endonuclease VIII: roles of the intercalation loop and the zinc finger. Biochemistry 45, 12039-12049. doi: 10.1021/bi060663e

Kumar, P., Sannigrahi, S., and Tzeng, Y. L. (2012). The Neisseria meningitidis ZnuD zinc receptor contributes to interactions with epithelial cells and supports heme utilization when expressed in Escherichia coli. Infect. Immun. 80, 657-667. doi: 10.1128/IAI.05208-11

Lewinson, O., Lee, A. T., and Rees, D. C. (2009). A P-type ATPase importer that discriminates between essential and toxic transition metals. Proc. Natl. Acad. Sci. U.S.A. 106, 4677-4682. doi: 10.1073/pnas.0900666106

Lewis, D. A., Klesney-Tait, J., Lumbley, S. R., Ward, C. K., Latimer, J. L., Ison, C. A., et al. (1999). Identification of the znuA-encoded periplasmic zinc transport protein of Haemophilus ducreyi. Infect Immun 67, 5060-5068.

Li, Y., Qiu, Y., Gao, H., Guo, Z., Han, Y., Song, Y., et al. (2009). Characterization of Zur-dependent genes and direct Zur targets in Yersinia pestis. BMC Microbiol. 9:128. doi: 10.1186/1471-2180-9-128

Lim, C. K., Hassan, K. A., Penesyan, A., Loper, J. E., and Paulsen, I. T. (2013). The effect of zinc limitation on the transcriptome of Pseudomonas protegens Pf-5. Environ. Microbiol. 15, 702-715. doi: 10.1111/j.1462-2920.2012.02849.x

Liu, J. Z., Jellbauer, S., Poe, A. J., Ton, V., Pesciaroli, M., Kehl-Fie, T. E., et al. (2012). Zinc sequestration by the neutrophil protein calprotectin enhances Salmonella growth in the inflamed gut. Cell Host Microbe 11, 227-239. doi: 10.1016/j.chom.2012.01.017

Liuzzi, J. P. (2005). Interleukin-6 regulates the zinc transporter Zip14 in liver and contributes to the hypozincemia of the acute-phase response. Proc. Natl. Acad. Sci. U.S.A. 102, 6843-6848. doi: 10.1073/pnas.0502257102

Loisel, E., Chimalapati, S., Bougault, C., Imberty, A., Gallet, B., Di Guilmi, A. M., et al. (2011). Biochemical characterization of the histidine triad protein PhtD as a cell surface zinc-binding protein of pneumococcus. Biochemistry 50 , 3551-3558. doi: 10.1021/bi200012f

Lucarelli, D., Russo, S., Garman, E., Milano, A., Meyer-Klaucke, W., and Pohl, E. (2007). Crystal Structure and function of the zinc uptake regulator FurB from Mycobacterium tuberculosis. J. of Biol. Chem. 282, 9914-9922. doi: 10.1074/jbc.M609974200

McDevitt, C. A., Ogunniyi, A. D., Valkov, E., Lawrence, M. C., Kobe, B., McEwan, A. G., et al. (2011). A molecular mechanism for bacterial susceptibility to zinc. PLoS Pathog. 7:e1002357. doi: 10.1371/journal.ppat.1002357

Meini, M. R., Gonzalez, L. J., and Vila, A. J. (2013). Antibiotic resistance in Zn(II)deficient environments: metallo-beta-lactamase activation in the periplasm. Future Microbiol. 8, 947-979. doi: 10.2217/fmb.13.34

Miller, W. T., Hill, K.a.W., and Schimmel, P. (1991). Evidence for a "cysteinehistidine box" metal-binding site in an Escherichia coli aminoacyl-tRNA synthetase. Biochemistry 30, 6970-6976. doi: 10.1021/bi00242a023

Murphy, T. F., Brauer, A. L., Kirkham, C., Johnson, A., Koszelak-Rosenblum, M., and Malkowski, M. G. (2013). Role of the zinc uptake ABC transporter of Moraxella catarrhalis in persistence in the respiratory tract. Infect. Immun. 81, 3406-3413. doi: 10.1128/IAI.00589-13

Nielubowicz, G. R., Smith, S. N., and Mobley, H. L. (2010). Zinc uptake contributes to motility and provides a competitive advantage to Proteus mirabilis during experimental urinary tract infection. Infect. Immun. 78, 2823-2833. doi: 10.1128/IAI.01220-09

Nikaido, H., and Vaara, M. (1985). Molecular basis of bacterial outer membrane permeability. Microbiol. Rev. 49, 1-32.

Ortiz De Orue Lucana, D., Wedderhoff, I., and Groves, M. R. (2012). ROSmediated signalling in bacteria: zinc-containing Cys-X-X-Cys redox centres and iron-based oxidative stress. J. Signal Transduct. 2012, 605905. doi: $10.1155 / 2012 / 605905$

Outten, C. E., and O'Halloran, T. V. (2001). Femtomolar sensitivity of metalloregulatory proteins controlling zinc homeostasis. Science 292, 2488-2492. doi: $10.1126 /$ science. 1060331

Outten, C. E., Tobin, D. A., Penner-Hahn, J. E., and O’Halloran, T. V. (2001). Characterization of the metal receptor sites in Escherichia coli Zur, an ultrasensitive zinc(II) metalloregulatory protein. Biochemistry 40, 10417-10423. doi: 10.1021/bi0155448

Panina, E. M. (2003). Comparative genomics of bacterial zinc regulons: enhanced ion transport, pathogenesis, and rearrangement of ribosomal proteins. Proc. Natl. Acad. Sci. U.S.A. 100, 9912-9917. doi: 10.1073/pnas.1733691100

Panina, E. M., Mironov, A. A., and Gelfand, M. S. (2003). Comparative genomics of bacterial zinc regulons: enhanced ion transport, pathogenesis, and rearrangement of ribosomal proteins. Proc. Natl. Acad. Sci. U.S.A. 100, 9912-9917. doi: $10.1073 /$ pnas. 1733691100

Pasquali, P., Ammendola, S., Pistoia, C., Petrucci, P., Tarantino, M., Valente, C., et al. (2008). Attenuated Salmonella enterica serovar Typhimurium lacking the $\mathrm{ZnuABC}$ transporter confers immune-based protection against challenge infections in mice. Vaccine 26, 3421-3426. doi: 10.1016/j.vaccine.2008.04.036

Patzer, S. I., and Hantke, K. (1998). The ZnuABC high-affinity zinc uptake system and its regulator Zur in Escherichia coli. Mol. Microbiol. 28, 1199-1210. doi: 10.1046/j.1365-2958.1998.00883.x

Pawlik, M. C., Hubert, K., Joseph, B., Claus, H., Schoen, C., and Vogel, U. (2012). The zinc-responsive regulon of Neisseria meningitidis comprises 17 genes under control of a Zur element. J. Bacteriol. 194, 6594-6603. doi: 10.1128/JB. 01091-12

Pesciaroli, M., Aloisio, F., Ammendola, S., Pistoia, C., Petrucci, P., Tarantino, M., et al. (2011). An attenuated Salmonella enterica serovar Typhimurium strain lacking the ZnuABC transporter induces protection in a mouse intestinal model of Salmonella infection. Vaccine 29, 1783-1790. doi: 10.1016/j.vaccine.2010.12.111

Pesciaroli, M., Gradassi, M., Martinelli, N., Ruggeri, J., Pistoia, C., Raffatellu, M., et al. (2013). Salmonella Typhimurium lacking the Znuabc transporter is attenuated and immunogenic in pigs. Vaccine 31, 2868-2873. doi: 10.1016/j.vaccine.2013.04.032

Petrarca, P., Ammendola, S., Pasquali, P., and Battistoni, A. (2010). The Zurregulated ZinT protein is an auxiliary component of the high-affinity ZnuABC zinc transporter that facilitates metal recruitment during severe zinc shortage. J. Bacteriol. 192, 1553-1564. doi: 10.1128/JB.01310-09

Rensing, C., Mitra, B., and Rosen, B. P. (1997). The zntA gene of Escherichia coli encodes a $\mathrm{Zn}$ (II)-translocating P-type ATPase. Proc. Natl. Acad. Sci. U.S.A. 94, 14326-14331. doi: 10.1073/pnas.94.26.14326

Rosadini, C. V., Gawronski, J. D., Raimunda, D., Arguello, J. M., and Akerley, B. J. (2011). A novel zinc binding system, ZevAB, is critical for survival of nontypeable Haemophilus influenzae in a murine lung infection model. Infect. Immun. 79, 3366-3376. doi: 10.1128/IAI.05135-11

Sabri, M., Houle, S., and Dozois, C. M. (2009). Roles of the extraintestinal pathogenic Escherichia coli ZnuACB and ZupT zinc transporters during urinary tract infection. Infect. Immun. 77, 1155-1164. doi: 10.1128/IAI.01082-08

Scrutton, M. C., Wu, C. W., and Goldthwait, D. A. (1971). The presence and possible role of zinc in RNA polymerase obtained from Escherichia coli. Proc. Natl. Acad. Sci. U.S.A. 68, 2497-2501. doi: 10.1073/pnas.68.10.2497

Shin, J. H., Jung, H. J., An, Y. J., Cho, Y. B., Cha, S. S., and Roe, J. H. (2011). Graded expression of zinc-responsive genes through two regulatory zinc-binding sites in Zur. Proc. Natl. Acad. Sci. U.S.A. 108, 5045-5050. doi: 10.1073/pnas. 1017744108

Simm, C., Luan, C. H., Weiss, E., and O’Halloran, T. (2011). High-throughput screen for identifying small molecules that target fungal zinc homeostasis. PLoS ONE 6:e25136. doi: 10.1371/journal.pone.0025136

Stork, M., Bos, M. P., Jongerius, I., De Kok, N., Schilders, I., Weynants, V. E., et al. (2010). An outer membrane receptor of Neisseria meningitidis involved in zinc acquisition with vaccine potential. PLoS Pathog. 6:e1000969. doi: 10.1371/journal.ppat. 1000969 
Subramanian Vignesh, K., Landero Figueroa, J. A., Porollo, A., Caruso, J. A., and Deepe, G. S. Jr. (2013). Granulocyte macrophage-colony stimulating factor induced $\mathrm{zn}$ sequestration enhances macrophage superoxide and limits intracellular pathogen survival. Immunity 39, 697-710. doi: 10.1016/j.immuni.2013.09.006

Taudte, N., and Grass, G. (2010). Point mutations change specificity and kinetics of metal uptake by ZupT from Escherichia coli. Biometals 23, 643-656. doi: 10.1007/s10534-010-9319-z

Waldron, K. J., and Robinson, N. J. (2009). How do bacterial cells ensure that metalloproteins get the correct metal? Nat. Rev. Microbiol. 7, 25-35. doi: 10.1038 /nrmicro2057

Wang, D., Hosteen, O., and Fierke, C. A. (2012). ZntR-mediated transcription of zntA responds to nanomolar intracellular free zinc. J. Inorg. Biochem. 111, 173-181. doi: 10.1016/j.jinorgbio.2012.02.008

Wang, D., Hurst, T. K., Thompson, R. B., and Fierke, C. A. (2011). Genetically encoded ratiometric biosensors to measure intracellular exchangeable zinc in Escherichia coli. J. Biomed. Opt. 16, 087011. doi: 10.1117/1.3613926

Wei, B., Randich, A. M., Bhattacharyya-Pakrasi, M., Pakrasi, H. B., and Smith, T. J. (2007). Possible regulatory role for the histidine-rich loop in the zinc transport protein, ZnuA. Biochemistry 46, 8734-8743. doi: 10.1021/bi700763w

Yang, X., Becker, T., Walters, N., and Pascual, D. W. (2006). Deletion of znuA virulence factor attenuates Brucella abortus and confers protection against wild-type challenge. Infect. Immun. 74, 3874-3879. doi: 10.1128/IAI.01957-05

Yatsunyk, L. A., Easton, J. A., Kim, L. R., Sugarbaker, S. A., Bennett, B., Breece, R. M., et al. (2008). Structure and metal binding properties of $\mathrm{ZnuA}$, a periplasmic zinc transporter from Escherichia coli. J. Biol. Inorg. Chem. 13, 271-288. doi: 10.1007/s00775-007-0320-0

Zalewski, P., Truong-Tran, A., Lincoln, S., Ward, D., Shankar, A., Coyle, P., et al. (2006). Use of a zinc fluorophore to measure labile pools of zinc in body fluids and cell-conditioned media. BioTechniques 40, 509-520. doi: 10.2144/06404RR02

Conflict of Interest Statement: The authors declare that the research was conducted in the absence of any commercial or financial relationships that could be construed as a potential conflict of interest.

Received: 01 October 2013; accepted: 11 December 2013; published online: 24 December 2013.

Citation: Cerasi M, Ammendola S and Battistoni A (2013) Competition for zinc binding in the host-pathogen interaction. Front. Cell. Infect. Microbiol. 3:108. doi: 10.3389/ fcimb.2013.00108

This article was submitted to the journal Frontiers in Cellular and Infection Microbiology.

Copyright (c) 2013 Cerasi, Ammendola and Battistoni. This is an open-access article distributed under the terms of the Creative Commons Attribution License (CC BY). The use, distribution or reproduction in other forums is permitted, provided the original author(s) or licensor are credited and that the original publication in this journal is cited, in accordance with accepted academic practice. No use, distribution or reproduction is permitted which does not comply with these terms. 